\title{
THE "HUMAN COLOUR" CRAYON: \\ INVESTIGATING THE ATTITUDES AND \\ PERCEPTIONS OF LEARNERS REGARDING \\ RACE AND SKIN COLOUR
}

\author{
Neeske Alexander \\ Stellenbosch University \\ neeskealexander@gmail.com
}

Elmarie Costandius

Stellenbosch University

elmarie@sun.ac.za

\section{ABSTRACT}

Some coloured and black learners in South Africa use a light orange or pink crayon to represent themselves in art. Many learners name this colour "human colour" or "skin colour". This is troublesome, because it could reflect exclusionary ways of representing race in images and language. This case study, conducted with two schools in the Western Cape, investigated Grade 3 learners' attitudes and perceptions regarding race and skin colour through art processes and discussion. The aim was to promote critical engagement with race in Foundation Phase educational contexts. Suggestions include changing the language used to describe skin colour, just recognition and representation of races in educational resources and the promotion of critical citizenship education. This research indicates the need to create practical curriculum guidelines to discuss race issues in the South African classroom.

Keywords: art; case study; critical citizenship; curriculum; educator training; Foundation Phase; identity; racism; skin colour

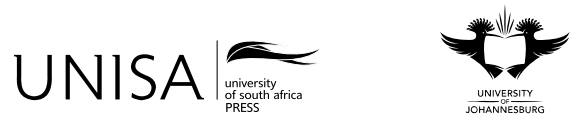

Education as Change 


\section{INTRODUCTION}

Awareness of just recognition and representation concerning different skin colours is growing in international contemporary society. In the second half of 2015, Unicode 8 was launched which included a range of different skin colour options for emoji characters and gestures used in social media and mobile applications (Warren 2015). In February 2016, Angélica Dass presented "The Beauty of Human Skin in Every Colour" at a TED (Technology, Education, Design) conference challenging the way we think about skin colour (TED 2016). In education, we cannot ignore the ways that race is represented and discussed in the classroom.

During my time as an educator in the Western Cape, I noticed that many learners depict themselves with white ${ }^{1}$ skin in drawings - even if their skin is brown or black. The crayon they use to do this is often named menskleur ("human colour") ${ }^{2}$ or "skin colour" ${ }^{3}$ This occurrence led me to reflect on the ways in which learners express their racial identity through art, as well as the possible thoughts they have concerning the naming of a single skin colour as menskleur ("human colour") in the presence of a variety of skin colours. The naming of a single colour as menskleur ("human colour") is troublesome within the context of post-colonial, post-apartheid South Africa, because it could perpetuate colonial and apartheid race hierarchies. This case study was an investigation of learners' and educators' attitudes and perceptions regarding the naming of skin colour in South African art classrooms in order to promote more just recognition and representation of races in Foundation Phase educational contexts.

Contemporary South African society constitutes a fertile ground for critical studies of race and racism (Stevens, Franchi and Swart 2006). An important aspect to consider when investigating learners' attitudes and perceptions regarding race and skin colour is the context of race and racism in South Africa. In addition, the current educational context, where various barriers to addressing race issues are present, should be considered. A theoretical framework of critical race theory (CRT), social justice and critical citizenship education was used to place the research within a certain field of enquiry.

1 In this article the terms "black", "coloured", and "white" refer to race and skin colour. These terms are acceptable to use in South Africa and are recommended in the style guide of Stellenbosch University (Stellenbosch University Language Centre 2014).

2 I translated the Afrikaans term menskleur as "human colour". If the Afrikaans term was velkleur I would have translated it as "skin colour". However, the common term used to describe the colour in question is menskleur ("human colour"). This contrasts the implied worth attached to personhood (to be "human colour" is to be human) with the possible dehumanisation caused by colonial projects (Hook 2003) and apartheid that classified non-"human colour" persons as inferior.

3 Similar naming has occurred in the USA. In 1962, Binney and Smith changed the name of a certain Crayola colour wax crayon from "flesh" to "peach" (Roth 2009). This signifies a "public recognition of race in such an ordinary product as the wax crayon" as well as the recognition of the ideological and racist bias embedded in the concept of the product (Roth 2009, 142). 
The aim of this research was to examine the ways in which racial identity is discussed and represented in Grade 3 art classrooms in order to promote critical engagement with race and skin colour in the Foundation Phase educational environment. A discussion of the data as well as of possible implications is given in order to reach this aim.

\section{Race in South Africa}

When discussing the naming of skin colour, it is important to define what is meant by race and racism. Race is a system of denomination dealing with the social construction of ourselves as members of a group categorised by the biological traits of heredity specifically skin colour and physical appearance (Oloyede 2009). Wolpe (1988 cited in Pillay 2009) describes race as a biological notion that defines social groups. According to Smedley $(1998,699)$,

race [as a social convention], has nothing to do with the intrinsic, or potential, qualities of the physically differing populations, but much to do with the allocation of power, privilege, and wealth among them.

Race can therefore be seen as a construction of social group identity based on biological characteristics. Race is the basis on which racialisation and the discourse of racism are defined.

"Racialisation" refers to the process by which meaning is attributed to features of the human body in order to construct difference and thereby justify inequality on the basis of race (Miles 1989 cited in Ratele and Shefer 2003, 94). Racial legacy is supported by codification and institutionalisation across all spheres of public culture, including visual and literary cultures, human categorisation, and pedagogical traditions (Amin 2012). During the apartheid regime the most significant determinant of identity was the race of the body (Ratele and Shefer 2003). According to Amin (2012), racism lies in the racial hierarchy mapped by historical practices of racialisation and the human compulsion to categorise. Racialisation is promoted through discourse.

Discourse is a key part of the functioning and reproduction of the ideology of racism (Duncan 2003). Hill (1998) argues that racism can be embedded in the speech of white people. Afrikaans was the dominant language used to promote and maintain the apartheid agenda. Certain terms such as menskleur could have roots in this discourse of superiority and inferiority. It could also continue the dehumanising process by excluding persons whose skin is different from the so-called human colour. Fanon (1970) emphasises the role that language plays in racial alienation, objectification and dehumanisation within the colonial agenda (Hook 2003). Racialisation is achieved through the discourse and language used to identify and justify racial categories. Racism exists as systems of domination and oppression that are reflected in the internalised superiority or inferiority of individuals (Santas 2000). In contemporary society, racialisation can occur even though official racism is no longer part of the governing structure. 
The end of the apartheid regime in South Africa in 1994 did not eliminate the history of racism (Stevens, Franchi and Swart 2006). In a post-colonial, globalised world new layers of structural racism are continuously created (James 2008). Racial beliefs (even when unstated) are shown by the way they are routinely practised in daily life (Santas 2000). South African society remains deeply racialised, even though racism is illegal (Stevens et al. 2006). "Race trouble"4 persists in South Africa as racial suspicion, conflict and threat (Durrheim, Mtose and Brown 2011, 1). The endurance of racial inequality, despite great efforts made in order to eradicate racism, is problematic (Durrheim et al. 2011). The way in which language perpetuates racist bias was of interest in this case study. Naming the colour of white skin "human colour" is an example of how racism can be embedded in the language used by society.

\section{Educational context}

The language used to name and discuss race and skin colour is important in educational contexts in South Africa. However, learners' educational contexts are not only influenced by language, but also by the visual images that accompany language. Language socialisation occurs when children acquire social skills and world views as they acquire language (Garret 2006; Schieffelin and Ochs 1986). Zimmermann, Levisen, Beck and van Scherpenberg (2015) argue that colour concepts are linguistic constructs and that the naming of "skin colour" is a result of language socialisation. Both language and visual culture are socially constructed and therefore influenced by dominant norms and ideals. The visual nature of contemporary society also affects identity formation (Ali 2012). Learners draw the human figure often and it continues to be a popular subject into adolescence (Cox 1993 cited in Wang 2014). The representation of skin colour in learners' art could therefore be influenced by dominant visual images and ideals of beauty. These aspects of racial identity should be discussed in classrooms.

Primary school classrooms can provide a space for engaging with race issues in South Africa. At the end of apartheid, government adopted a mandate to reverse policies of overt racial inequity in education (Fiske and Ladd 2004). The South African Department of Basic Education (2011) promotes active and critical learning that is sensitive to issues of diversity, inequality and race. Learners are expected to respect the rights of others and to show tolerance for cultural diversity in order to contribute to a democratic society. The curriculum suggests that two-dimensional artwork be used to enrich learners' experience of the real world through visual and sensory stimulation, discussion and questioning, and through encouraging the drawing of the physical body (Department of Basic Education 2011). This curriculum approach is particularly emphasised in the Foundation Phase of education (grades $\mathrm{R}$ to 3 ). The curriculum documents envisage a

4 "Race trouble" is defined as "a social psychological condition that emerges when the history of racism infiltrates the present to unsettle social order, arouse conflict of perspectives and create situations that are individually and collectively troubling" (Durrheim et al. 2011, 27). 
learner who can go beyond the racist policies of the past by being governed by respect for individual worth, fairness and justice (Seroto 2012). While these curriculum outlines seem promising, barriers exist that prevent learners and educators from addressing race in schools.

Deep-rooted trauma due to the past and feelings of inadequacy cause educators to either avoid classroom dialogue concerning different racial identities in South Africa, or to perpetuate inferiority or superiority practices in the classroom (Weldon 2010). "Colour-blind" ideologies also prevent educators from realising how race dictates social injustice (Banks 2001, 12). Not only are educators wary of addressing issues of race and skin colour, but learners who have been socialised in the post-apartheid context do not necessarily have better intercultural interaction than older South Africans who have been socialised in the apartheid context (Durrheim and Dixon 2010). There is, therefore, a discrepancy between the suggested curriculum outlines to address race issues and the practical implementation of these outlines in the classroom.

\section{THEORETICAL FRAMEWORK}

Educational researchers aim to understand and work towards eliminating injustice and oppression in schools. Injustice and oppression are viewed as a situation or dynamic that benefits certain identities or ways of being in society, while marginalising others (Kumashiro 2000). A broader view of the dynamics of injustice and oppression is necessary in the practices of teaching and learning as well as the purposes of education (Kumashiro 2000). With this in mind, the investigation of learners' attitudes and perceptions regarding skin colour was informed by the theoretical perspectives of CRT, social justice and critical citizenship education within the historically influenced context of South Africa.

CRT focuses on the ways in which race and racism exist in educational contexts. This theory allowed me to view the investigation critically through the lens of race. Social justice relates to racial representation and recognition. Social justice is used as a framework for recognising the ways in which race and racism affect education. Critical citizenship education promotes social justice and is used to understand race and racism from the angle of responsibility and belonging. All three theories are therefore intertwined in my investigation of the attitudes and perceptions of learners regarding skin colour.

CRT study plays a necessary role in interrogating race and racism in education (Lynn and Parker 2006). According to Delgado and Stefanic (2001), racism is difficult to address in research due to its ordinary nature. CRT therefore aims to examine the persistent racial inequalities within teaching practice, the experiences of marginalised learners and the effect of race-conscious education policy (Stovall 2010). CRT scholars aim to study and transform the relationships between race, racism and power. This includes "colour-blind" (Banks 2001, 12) ideologies, which involve the refusal to see 
race. The idea that everyone is the same under the skin and that racism is therefore no longer something to be addressed fails to recognise the differences underpinned by race. Race is not an innocent construct, but affects every aspect of society, including our friends, our movement, and our identities (Frankenberg 1993). Race should not be ignored. CRT is a useful perspective when investigating the historical impact of colonialism and apartheid in South Africa because these systems were largely based on what CRT emphasises as social constructs of race, interest convergence and the centrality of narrative. CRT points towards a commitment to social justice.

Social justice requires redistribution of resources, recognition of identities (Fraser 1996) and political representation (Fraser 2009). According to Ayers (2010), social justice is not only about the just distribution of wealth and power, but also about recognising each person as fully human while disrupting the structures of marginalisation. Social justice includes goals of equity, awareness and social literacy. It is concerned with changing unjust social patterns of representation, interpretation and communication, such as cultural domination, non-recognition and disrespect (Fraser 1996). These concerns hold value in terms of the unjust representation of people of colour ${ }^{5}$ in South Africa in the past and in contemporary settings. Social justice can be advanced through critical citizenship education.

Critical citizenship education promotes a common set of shared values (acceptance, human rights, democracy, social justice and social reconstruction), which prepare learners to live together in diverse societies (Johnson and Morris 2010). According to Nussbaum (2002), citizenship education is the cultivation of humanity towards the purpose of producing citizens who think for themselves, argue with tradition and have sympathy for the lives of others different to their own. According to Cross (2010), the educational curriculum can analyse how racism maintains inequities and injustice as well as interrogate and oppose social norms that perpetuate racism in both invisible and explicit ways in the classroom. Critical citizenship education may therefore be useful for naming racism and teaching strategically to confront racism in education. This could enable learners to live together in a racially and culturally diverse South Africa.

\section{METHODOLOGY}

The investigation of learners' attitudes and perceptions regarding the naming of skin colour followed an interpretive approach. The case study involved learners and educators as participants and therefore ethical conduct was vital. Qualitative datacollection methods were applied.

The research methodology involved a non-probability (Mouton 2001) sampled case study providing empirical data. The parameters of this research included two

5 "People of colour" is an accepted term in colloquial English in South Africa. 
dual-medium, ${ }^{6}$ co-ed $^{7}$, ex-Model $\mathrm{C}^{8}$ schools in the Western Cape. Four Grade 3 classes were chosen to participate in the study - one English class and one Afrikaans class per school. In addition, the educators of the respective classes as well as the educational psychologist, who works at both schools, participated. The selected sample contained 56 Afrikaans learners and 49 English learners. Of the Afrikaans learners, 59 per cent were white ${ }^{9}$ and 41 per cent were coloured. Of the English learners, 47 per cent were white, 37 per cent were coloured and 16 per cent were black. All adult participants in the study were white.

Table 1: Breakdown of selected sample of learners according to school (1 or 2), language ( $\mathrm{A}$ or $\mathrm{E})$ and race $(\mathrm{B}, \mathrm{C}$ or $\mathrm{W})$

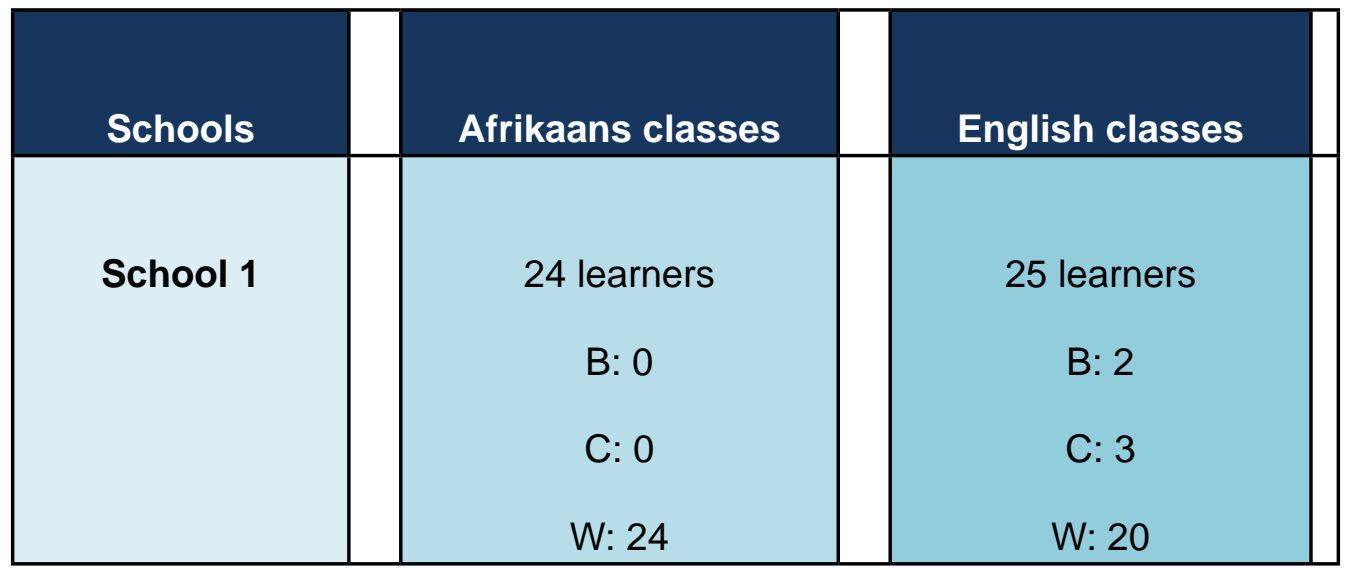

6 Dual-medium language instruction allows learners to receive teaching in one of the two languages offered at a school. Afrikaans and English were the languages of teaching and learning.

7 Co-ed refers to schools attended by both female and male learners.

8 Ex-Model $\mathrm{C}$ is the term used for schools that were reserved exclusively for white learners and educators during the apartheid regime. As a result, many of these schools still have facilities and resources of a high standard.

9 Racial categories such as black, coloured, Indian and white, even though they originate from the apartheid policies, remain relevant. This relevance is due partly because they have become part of the language for post-apartheid redress and partly because of the cultural meaning they retain in everyday life in South Africa (Seekings 2008). For these reasons I use racial categories when discussing skin colour. Even though these racial terms can potentially re-inscribe race, they also offer a means to speak about new possibilities and reflect power relations (Stevens et al. 2006). 


\begin{tabular}{|c|c|c|c|}
\hline School 2 & 32 learners & 24 learners \\
& B: 0 & B: 6 \\
C: 23 & C: 15 \\
W: 9 & W: 3 \\
\hline
\end{tabular}

The position of children or learners in the research process, safe space and participants' preferred language were considered. Mayall (2000) emphasises the subordinate and marginal positions of children compared to adults and the importance of considering this imbalance during the planning and implementation of the research process. According to Loxton (2009), settings that are familiar and have a non-intimidating atmosphere should be chosen for research with children. As a measure in case the research process created any emotional discomfort for the learners, the school psychologist working at both School 1 and School 2 was available to see the learners. The research was approved by the Departmental Ethics Screening Committee at Stellenbosch University.

Data were mainly collected from three art lessons with each class (45 minutes to 1 hour each) through observation, analysis of art products and processes, class discussions, and verbal and written reflections. Interactions with the learners took place during school time and formed part of their Life Skills (Creative Arts: Visual Arts) curriculum. Semistructured interviews were conducted with educators and the educational psychologist.

Data were captured by audio recordings of learners' communication during lessons and interviews with educators. Audio recordings were transcribed verbatim for analysis. Written responses and reflections were gathered from learners, field notes were taken and visual products were collected. Participants' responses were coded in the following way: 1 (School 1), 2 (School 2), E (English), A (Afrikaans), L (Learner), Ed (Educator), $\mathrm{P}$ (Psychologist) and R (Researcher). All responses in Afrikaans were translated into English. Data gathered were analysed interpretively while aiming to achieve validity and trustworthiness.

Data were analysed using inductive content analysis. The data were taken raw, processed, and analysed. Inductive reasoning moves from particular details toward more general theories. Content analysis involves investigating all data in detail. During this analysis it was important to be aware of the possibility of silencing certain opinions of participants due to researcher's bias (Ali and Kelly 2012). Following this investigation the data were grouped according to similarities. Attention was given to how ideas were repeated in different ways as well as to the nuances that surfaced within the data. Data groups were then combined to build a few overarching themes concerning the attitudes 
and perceptions regarding race and skin colour. The data are presented and discussed in the following section.

\section{PRESENTATION AND DISCUSSION OF DATA}

The following discussion of data relates to the learners' responses to the naming of skin colour as well as the attitudes and perceptions that surfaced during data analysis. Attitudes and perceptions include learners' preference for light skin colour and the difficulty of talking about race. In addition, "colour-blind" ideologies (Banks 2001, 12) and the problem of naming skin colour were examined.

\section{Responses to the naming of skin colour}

Before any discussion took place concerning the naming of skin colour, the learners were asked to write down the names of the colours of the retractable wax crayons they use in school. The sixth crayon from the bottom is the colour that was of specific interest in this case study (see Figure 1).

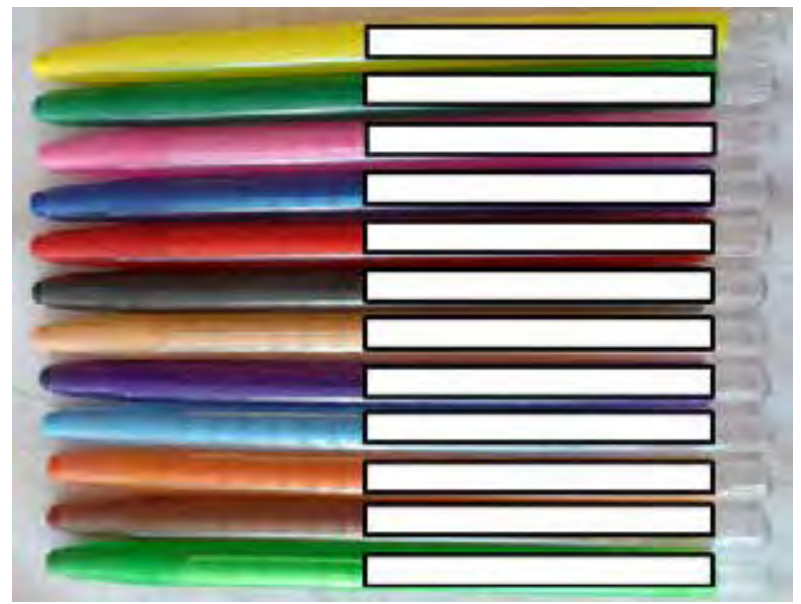

Figure 1: Sheet for naming the colours of crayons

There was a significant difference in the naming of the colour used for white skin between the English classes and the Afrikaans classes. While 82 per cent of the learners in the English classes named the colour "peach", 91 per cent of the learners in the Afrikaans classes called it menskleur. Therefore, while approximately 18 per cent of the English learners named the colour "skin colour", the majority of the Afrikaans learners used naming such as menskleur. 
The naming of skin colour also occurred during the process where the learners mixed their own skin colour using paint. These names included "human colour" or "skin colour" (most often), "peach" (often), "pink" and "brown". This can be seen in the following comments: "Make skin colour" (1EL3), "Yoh, he's got "human colour"" (2AL3), "My skin colour is peach" (1EL13), "How do the people get brown?" (2AL8) and "Teacher, it is a light pinky colour - "human colour"" (2AL14). Learners' skin colours form part of their identity. The learners described skin colours by referring to "my colour" and "your colour". This is reflected in comments made by learners 2EL12, 2EL2 and 2EL3 respectively: "Now it's going to be pretty hard to make my colour, I'm peach", "That's not looking like your colour skin at all" and "Miss, this colour is my colour".

When asked why people call the crayon "human colour" or "skin colour", the learners stated, "It is almost like "human colour" (2AL2) and "It looks just like skin colour" (1EL8). They wrote, "White people are born that way" (2EL2), "It is white people's colour" (2AL20) and "It is the closest to a white person's skin" (2AL13). Common answers also included, "There are more white people" (2EL12), "Most people are "human colour" (1AL4), "Most people are white" (1AL15), "It is everyone's colour" (2AL21) and "Lots of people have the same, but some have brown" (1EL17). Some learners felt, "Because some people are white it is fine to call it 'skin colour"" (2EL8) and "Everyone calls it that" (2AL22). The reasons provided by the learners for the naming of the colour could be summarised as follows: It is named "human colour" or "skin colour" because it is accepted and because it is the colour of white people who are (according to the learners in both schools) in the majority.

One could draw a parallel between Afrikaans as the language used to promote the apartheid agenda and Afrikaans as a language used to name exclusively white skin colour "human colour". The issue of racial identities in the classroom and the naming of skin colour is, however, not only relevant to Afrikaans educational settings. Hidden ideas reflecting the perceived superiority of "whiteness" were also seen in discussions with the English classes. One such example is when Learner 1EL12 labelled "peach" skin colour (white skin colour) as the "nice" skin colour in Extract 1 below.

\section{Extract 1}

1EL12: You can't just tease other people because you have the nice skin.

$\mathrm{R}: \quad$ Which one is the "nice skin"?

1EL12: $\quad$ Peach.

It is clear from the data that learners participate in the naming of "human colour" or "skin colour" in a manner that reflects "whiteness" as a dominant narrative and that they view the white population as the majority. The learners' perceptions that "There are more white people than brown people" (1AL7) could be caused by their experiences 
in a mostly white environment as well as visual influences that promote "whiteness" as dominant (including Western media). Both schools in this case study have an overwhelming majority of white teaching staff. In the Western Cape, where this case study was conducted, the population groups are represented in the following manner: black South Africans (29\%), coloured South Africans (53\%), Indian or Asian South Africans (1\%) and white South Africans (17\%) (Statistics South Africa 2014, 72). It is clear from these statistics that white people are in no way the majority population group in the Western Cape. Dominance is therefore not based on number, but on historical constructs. Grade 3 learners therefore seem to have a skewed concept of the representation of races in South Africa. This could influence the ways in which they think and speak about race issues in the classroom. Learners also do not seem to realise the past and current political implications of naming one skin colour menskleur.

All four educators (2AEd, 2EEd, 1AEd and 1EEd) noticed that the learners named the colour for white skin "human colour" or "skin colour". Most of the educators felt that the naming of a certain colour as "human colour" or "skin colour" starts at an early age when learners enter a semi-structured schooling environment such as preschool. This can be seen in Extract 2 .

\section{Extract 2}

R: $\quad[$ W] hat do the learners in your class call this colour?

1EEd: [Three-second pause] "Human colour"...I have...I haven't noticed it for a while...I think they use [the name] more when they are younger...it comes from a young age with them...from preschool. I don't know where - whether their parents teach it to them or what, but obviously for a white child it is "skin colour", but for a brown child it isn't.

Mentioning that the naming starts in pre-school or that learners pick it up from their parents possibly allows educators to avoid taking responsibility for the naming of race in their classrooms. This is understandable when one considers the complicated nature of race discussion in post-apartheid South Africa.

In reference to CRT, Delgado and Stefanic (2001) note that race is embedded in and affects ordinary life - particularly narratives by the dominant race. According to Frankenberg (1993) and Arber (2008), "whiteness" is by nature exclusionary of all that is not white. "Whiteness" then becomes the norm that is simultaneously overlooked and universalised within Western narratives (Arber 2008). In South Africa, Afrikaans texts were dominant within the education system during apartheid (Abdi 2002). Naming the colour representing white skin "human colour" or "skin colour" is an example of how "whiteness" is universalised. This naming is exclusionary. Learners are influenced by these dominant narratives and educators find it difficult to challenge the current way in which skin colour is named. 


\section{Preference for light skin colour}

The learners showed a preference for light skin colour in their self-portraits and in the way they spoke about the process of mixing the colour of their skin. This should be considered when aiming to develop positive racial identity and just recognition and representation of races in educational contexts.

The learners used retractable wax crayons to create self-portraits. While creating self-portraits and mixing their own skin colour, many learners used lighter colours for their skin (see Figure 2). The learners who used lighter colours for the face or who mixed colours used the brown crayon and the so-called human colour or skin colour crayon to draw and colour their skin (Figure 2). Some of these learners used the brown crayon, but coloured their faces very lightly or left their faces white (Figure 2). It is possible that these learners view lighter skin as more beautiful.

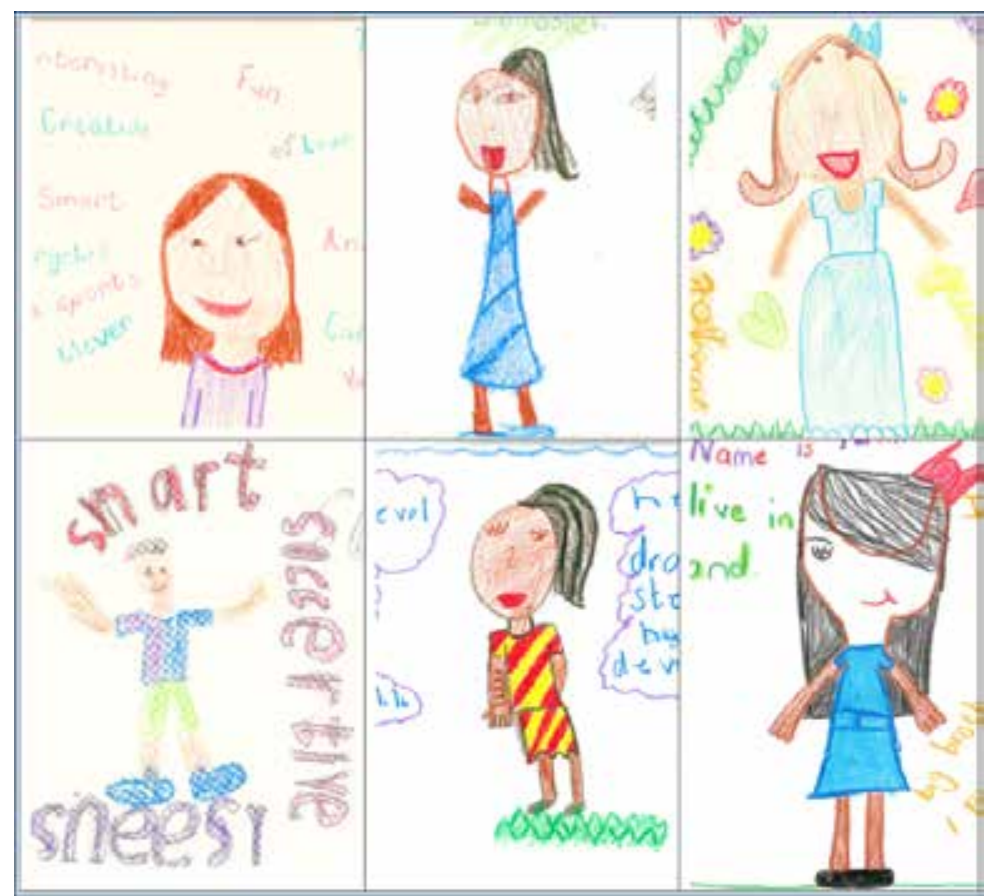

Figure 2: Self-portraits by learners who used lighter colours or who mixed colours

The reluctance to use dark colours to colour their faces could also be a strategy to "blend in" with the dominant visual culture. The psychologist working at both schools mentioned that learners avoid colouring their skin using dark colours in pictures: 
P: Some children will use [the so-called "human colour" crayon] to colour in people, whereas others will leave the skin part of people white...Even black children mostly leave the skin part of people white. I very rarely see black or coloured children that colour the skin a darker colour.

Some of the black and coloured learners used the so-called human colour or skin colour to draw and colour their pictures (see Figure 3), even though it is not an accurate representation of their skin colour.

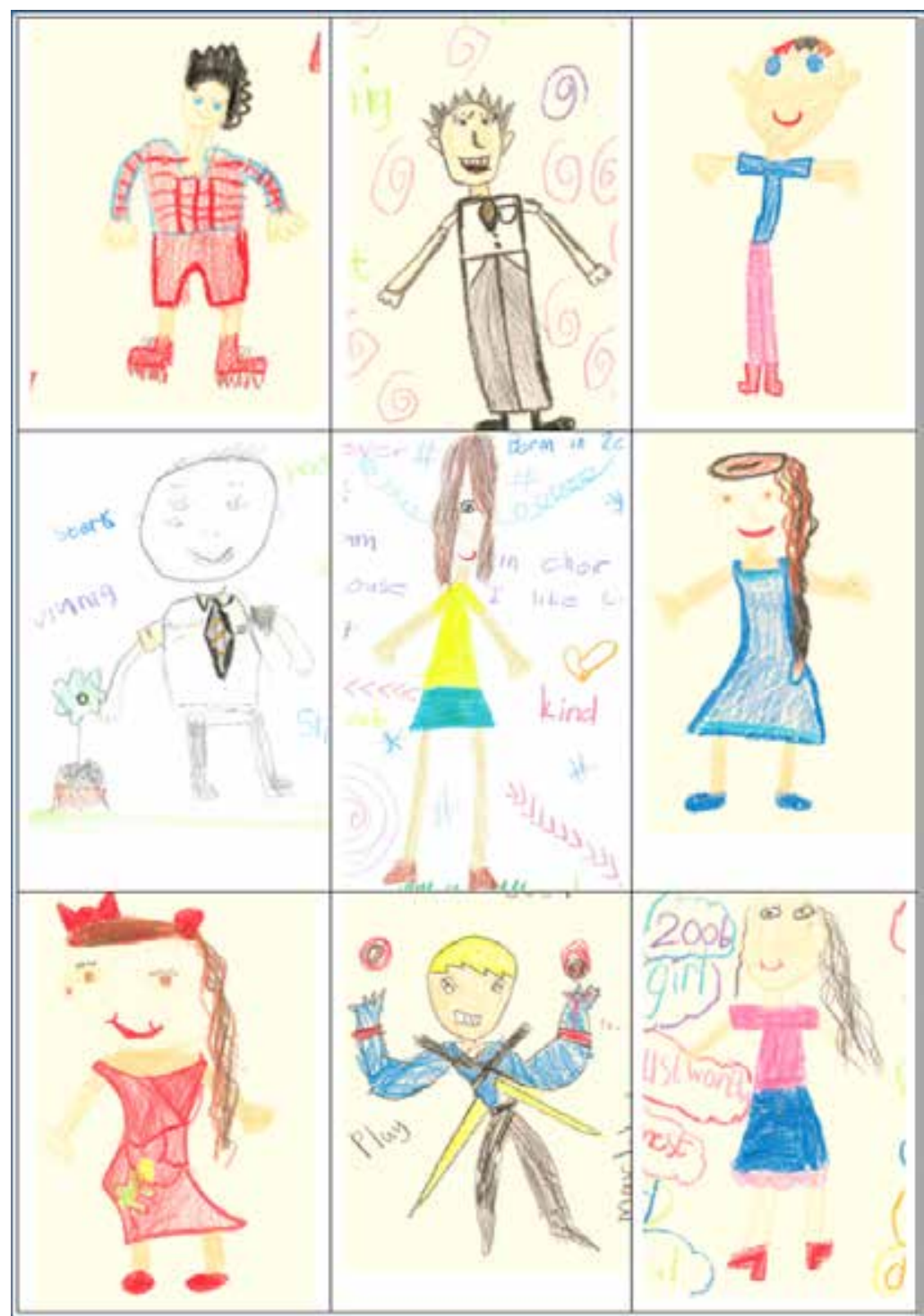

Figure 3: Self-portraits by black and coloured learners who used the so-called human colour or skin colour to draw themselves 
These portraits could indicate the learners' identification with the dominant ideals of beauty. It could also show a desire to assimilate into the "white hegemony" (Belluigi 2014, 350). When black or coloured learners represent themselves as white in selfportraits, it may expose a negative association with their racial identity. The learners' discussions while mixing their skin colours also revealed a preference for lighter skin colours. This can be seen in extracts 3 and 4 .

\section{Extract 3}

2AL16: Yes, you're not human colour, you're brown!

2AL14: Now how does a person get my brown?

2AL16: Easy!

2AL14: That's human colour there... This is my brown, that's not my brown. I'm light.

\section{Extract 4}

2AL9: Oh, how did you make that "human colour"?...Yes, I'm also making it now.

2AL25: The white and the red and the yellow.

2AL9: I'm going to make it a bit lighter, I'm not that dark.

The extracts show that these learners are aware of their own skin tone and the skin tones of the other learners. Some conflict regarding the naming of race was present during the art process. Extract 5 shows how sensitive race identification can be. Two coloured learners were mixing the colour of their skin, when one of the learners mentioned that the other should add black to their paint. Even a hint towards being black was taken with much offense.

\section{Extract 5}

$\begin{array}{ll}\text { 2AL7: } & {[\ldots] \text { Black }-} \\ \text { 2AL17: } & \text { You! } \\ \text { R: } & \text { What are you saying? } \\ \text { 2AL17: } & \text { Teacher, he thinks I'm black - } \\ \text { 2AL7: } & \text { No, teacher, she's a person, jis, I didn't say she's a black person - } \\ \text { 2AL17: } & \text { You lie. You lie. }\end{array}$


R: What did you really say?

2AL7: Teacher, she said I must mix black to -

2AL17: He's lying, teacher, he said I was black first!

2AL7: Yoh [name of learner], you're lying!

Interviews conducted by Durrheim et al. (2011) showed that many South African participants viewed "blackness" as more negative than "whiteness". According to Fanon (1970), these outlooks stem from a colonial view of "blackness" as negative. Colonial constructions of race may still impact the ways in which race is discussed or avoided in educational settings. The devaluation of certain skin colours can lead to possible psychological damage within learners and a desire to assimilate to the dominant ideal of beauty (Hook 2003). Quotations from the learners show how they participate in ranking lighter skin colours above darker skin colours.

According to Tatum (2001 cited in Milner 2007), the development of positive racial identity that is not based on superiority or inferiority is very important for all race groups in a race-conscious society. The building of this positive racial identity is a lifelong process. It often requires replacing stereotypes and misinformation regarding our own races and those of others. This process needs to be supported in schools. It is important for South African learners to develop a positive racial identity. Just recognition and representation of different races in the language used to describe skin colour could foster this positive racial identity.

Roth (2009) recommends two possible strategies for achieving just recognition and representation of different races in the classroom. The first is an adjustment of product design to allow learners to capture and reproduce a variety of skin tones successfully. The second is the development of a new standard of skin colour where the range is the norm and where all depictions of bodies facilitate this range. These strategies would have to be complemented by changes in school curricula and discourses about race and skin colour at home, at school and in the media. The establishment of a colour continuum, as opposed to whiteness as a default reference point for skin colour production, could be crucial in fostering a new way for learners to think about race and skin colour (Roth 2009). These suggestions could be followed in South African educational contexts where representations of race can still become more inclusive in an effort to reflect the population accurately. It should be noted that inclusive representations of race need to be accompanied by inclusive and just ways of talking about race and confronting racism.

\section{Difficulty of race}

The context of post-apartheid South Africa creates difficulties when discussing race. The naming of "human colour" or "skin colour" as well as black and coloured learners 
representing themselves as white in drawings are examples of troubling race-related situations. The specific context of this case study could have added to the difficulty of discussing race in the classroom, because all educators involved were white and most of them taught learners from a variety of races.

There was a sense of discomfort when discussing the naming of skin colour with educators. Elements of guilt and shame associated with the naming of skin colour in educational contexts could be present because educators - even if they realise the unjust nature of the naming - are wary of addressing issues of race in the classroom. Frustration and feelings of incompetence about discussing South Africa's past also influence educators' attitudes towards race. The following quote shows how an educator recodes "race" as "culture".

1AEd: $\quad[R]$ ather talk about culture than to say black people, because I never know how to deal with this - it is uncomfortable for me, I really do not like it...I get upset when you have to talk about...there are situations where one has to talk about things from the past. And how do you explain it away? How do you explain it?...I've learned to use culture rather than saying... yes...black and white and coloured people... Because it is a difficult thing.

I used art lessons as a tool to address difficult race issues with the learners. The learners were asked at the end of each art lesson how they felt. Most of the learners said that they enjoyed the lessons. During the art processes, the learners spoke about skin colour quite freely and openly. Extract 6 below shows a learner who is confident in mixing her skin colour because she practised it before in an art lesson. Art can therefore be used to teach learners how to represent their skin colour in an accurate way.

\section{Extract 6}

2EL10: I know how to make light brown, because at my old school I used to paint. I know how to make it.

2EL16: Did you make light brown?

2EL10: $\quad$ Yes...the teacher taught us.

Art classrooms can be used as spaces for addressing complex issues such as race in a non-threatening way, because most learners enjoy art and are able to express themselves freely through artistic processes. During the class discussions following the artistic processes, however, the learners became more wary of talking about race.

The learners felt uneasy about discussing race. The data show that some learners did not want the naming of skin colour to change. During separate class discussions, two coloured learners mentioned, "We shouldn't do anything" (2EL9) and "Just leave it alone" (2AL2). Perhaps black and coloured learners did not want their race or their difference from "whiteness" to be emphasised. Comments such as, "Teacher, I was wondering whether black is a "human colour"' (2AL17) could imply that the research 
confused the learners. Even though care was taken to discuss race openly with the learners and even though a "member check" (Janesick 2000, 393) was done to ensure that the learners' comments were accurately understood, there still remains a possibility that the research process caused some discomfort for the learners by making them aware of the injustice of the naming of "human colour" or "skin colour". It is also possible that the research process gave learners an experience of worth by allowing them to talk about their own opinions and feelings regarding the naming of skin colour and race. Learners could have gained a better understanding of different viewpoints as well as confidence in addressing sensitive issues.

Questions about race and racism involved some uneasiness for all the participants. As the researcher, I aimed to address race issues with as much sensitivity and respect as possible. This was difficult, because the questions I asked exposed the possible problem of an established practice in the naming of skin colour in the classroom. As a white person I do not know what it is to be black or coloured. Santas (2000) notes that white teachers of anti-racism may be doubly prone to failure because of an internalised superiority. Being aware of this, I sought to investigate the Grade 3 learners' attitudes and perceptions in a manner that allowed all the learners the chance to express their feelings and opinions. The difficulty of speaking about race in a mixed racial context where those with most power (the adults) were all white could have caused some opinions and feelings to be silenced.

Race and racism are present in educational settings - often in invisible or hidden ways. The difficulty of discussing race may lead to the acceptance of perpetuated racism and the avoidance of confrontation with racist practices. The inability to notice the ways in which institutionalised racism privileges some groups while it disadvantages others may hinder educators in eliminating racial inequity in schools (Banks 2001). Social justice in classrooms involves fair recognition of and respect for learners' racial identities wherever skin colour is represented. Social justice also involves addressing the language used to name skin colour and finding ways to allow learners to talk about race in South Africa. Educators play a key role in fostering this challenging dialogue.

\section{See no colour/ difference}

Most educators in this case study felt that learners should all be treated the same regardless of differences in culture or race. One educator mentioned that they, "[D]on't see colour" (2EEd). The idea of "treating everyone the same" is problematic, because the treatment could contain bias favouring certain dominant structures.

Educators' responses reflected "colour-blind" (Banks 2001, 12) ideologies. Colour-blind perspectives of race view learners as "all the same under the skin" and promote similar treatment of all learners irrespective of their race (Frankenberg 1993). This excuses educators from dealing with the complicated and challenging task of addressing race issues in the classroom. Comments such as, "Just because someone is 
from a different culture we don't do it differently" (1AEd) could imply the invisibility of difference and the devaluation of culture and race.

Treating all learners "the same" generally does not achieve social justice in the classroom, because it may encourage learners to assimilate to dominant norms. This assimilation works against fostering a positive racial identity. Educators should question to what degree social justice is achieved within the colour-blind classroom (Stoll 2014). Critical citizenship education could provide a framework for promoting a common set of shared values such as tolerance and social justice while engaging with difference in the classroom. Adopting these values may prepare learners to live together in diverse societies (Johnson and Morris 2010).

\section{Is the name "human colour" or "skin colour" a problem?}

Naming a single colour "human colour" or "skin colour" excludes other skin colours present in classrooms in South Africa. One educator agreed that this naming is "wrong [because] there are many different "skin colours" (1EEd). Other educators generally felt that it is just something learners do. Some learners felt that the naming of white skin as "human colour" was acceptable. Other learners realised that it excludes black and coloured people. Homogenous race groups treated this topic differently to groups of different races. This will be discussed below.

Some learners felt that the name "human colour" for a colour used to draw white skin is acceptable. This could indicate that learners accept the norm without realising the injustice it creates. The learners' comments included, "It is [just] a crayon" (2EL4), "There is also brown" (2AL12) and "Not all people are brown" (2AL14). The learners' responses may also reflect a wariness of discussing topics related to race.

Some learners felt that the name "human colour" was unacceptable. Their comments included, "Some people are not that colour" (2EL1), "Not everyone is 'skin colour" (1EL13) and "Not everyone is "human colour" (2AL17). These learners realised that saying some people are "human colour" and some people are not implies a "lesser humanity" for those excluded. This realisation promotes the Department of Basic Education's (2011) goal of active and critical learning that is sensitive to issues of diversity, inequality and race. It also suggests that Grade 3 learners can move beyond the racist policies of the past while being governed by respect for individual worth (Seroto 2012). These reflections were primarily from white learners in the Afrikaans class in School 1.

The Afrikaans class in School 1 did not have any black or coloured participants. The learners in this class spoke about race issues with more ease than the learners from the other classes. They presented ideas such as, "We must make new 'human colours'... that look the same as all the people's colours, but it will take many, many colours just to get those people's colours, but then at least we have everyone's in the world" (1AL18) and "[We] must talk about it!" (1AL9). Could a homogenous race context create a more comfortable atmosphere for discussing race issues? It may be easier to speak about race 
from a perceived dominant white position. The learners from racially diverse classes often suggested that the naming of skin colour is unproblematic. They tended to avoid talking about race. This could indicate that "race trouble" (Durrheim et al. 2011, 23) becomes more pronounced when a diverse racial group attempts to discuss race issues.

\section{IMPLICATIONS}

Baszile (2010) suggests two important aspects of contemporary education. The first is diverse representation in the curriculum and accurate representations of the histories and perspectives of minority or previously oppressed groups. The second is the facilitation of an understanding of diverse racial and cultural worldviews among educators. Implications drawn from the findings of the case study relate to the language used to describe skin colour and the representation of skin colour in educational resources as well as educators' responses to race. Educators should foster dialogue, but should also consider learners' tendencies to avoid race-related discussion. In addition, critical citizenship education and artistic processes should be advanced in educator training and research. Clear curriculum guidelines should also be created and implemented in Foundation Phase classrooms in South Africa.

The language used to describe white skin colour should be revised. Different descriptions can be suggested to learners, such as "peach", "coral", "beige", "cream", "light orange" or "pinky orange". Names for brown and black skin colours can include "cinnamon", "terracotta", "umber", "soil", "wood", "sand", or "hazel". Merely changing the name, however, does not eliminate underlying race issues with regard to the preference for light skin colour or the dominance of white hegemony. Educators should strive to build a positive racial identity within learners by recognising different races and cultures. This should be evident in educational media used in the classroom.

Educators are cautious of addressing race in the classroom and they tend to "treat all learners the same" regardless of their differences. Educators should consider whether this achieves social justice. Treating all learners as if they are from the dominant cultural group (in this case for instance as white) does not foster a safe and comfortable environment for all learners. In classrooms, efforts should be made to value all races and cultures equally. This will only be possible when educators reflect on their own race and culture. Educators should realise the ways in which their own racial identity and their ideas about race can perpetuate personal agendas and value systems in the classroom. Differences regarding class, language and gender should be given similar sensitive attention.

Educators should be sensitive to learners' feelings of avoidance. When addressing race in educational environments, it is important to be aware of power imbalances. Learners' willingness to discuss race should be taken into consideration, especially where learners of a certain race are in the minority. The role of the educator is critical in this process. Conflict that arises from the discussion of race issues should be resolved in a manner that respects learners' differences. It may be challenging to create a 
healthy and safe atmosphere for discussing race issues in the classroom, but continuous opportunities for learners to engage in dialogue could work towards this goal.

If educators utilise critical citizenship education and non-threatening techniques such as artistic processes, singing, theatre, stories and role-playing it may help learners to engage with race issues in a safe manner. Educators, however, may not be aware of the principles and implementation of critical citizenship education. They may also feel ill-equipped to use artistic processes in the classroom. Workshops and resources could therefore be created in order to promote critical citizenship education. In addition, more research could be done to determine how artistic processes can help learners and educators participate in discussions about race. Educators-in-training should be equipped to deal with race issues in the classroom. Tertiary education facilities could provide training in critical citizenship education as well as various techniques such as open dialogue and artistic processes.

The current curriculum guidelines as prescribed by the South African Department of Basic Education (2011) contain ideals based on critical citizenship education, but these remain relatively vague. Clear and practical steps should be taken to achieve these ideals. The curriculum does not provide clear guidelines on how to address race in an honest and respectful manner. Policy makers and curriculum creators could consider including specific guidelines for addressing race in the classroom. Every educational context differs and therefore a programme that achieves success in one school may not be successful in another school. A forum for role players such as educators, therapists, parents, policy-makers, governing bodies and academics could be created in order to share ideas and stories for best practice.

\section{CONCLUSION}

The aim of this research was to promote a more just educational context concerning the recognition and representation of race. This investigation required a critical confrontation with almost invisible forms of racialised meaning (Arber 2008). According to Seekings (2008), there are still too few studies on how racial identity is understood in the lived experience of South African learners. This study investigated Grade 3 learners' attitudes and perceptions regarding skin colour in two ex-Model C schools in the Western Cape. The process engaged the learners by questioning the naming and representation of skin colour, while attempting to create a safe space for the learners and educators to express their experiences of racial identity, both visually and verbally.

Responses gathered from the learners unmasked the problems regarding current expressions of racial identity. The findings of this case study cannot be generalised across all schools, but may provide useful insights into the attitudes and perceptions of learners and educators regarding race. This research therefore contributes to new understandings of how learners and educators view and name race in the post-apartheid South African classroom. The research also contributes to practical methods of using art and dialogue in the Foundation Phase classroom. 
Implications based on the findings and conclusions include changing the language used to describe skin colour, providing just recognition and representation of different races in educational resources and promoting increased self-reflection by educators. The findings and conclusions also point to the importance of the promotion of critical citizenship and artistic processes in educator training and the creation of clear and practical curriculum guidelines for addressing race.

Further research could investigate broader cases. This could involve schools that use different languages for teaching and learning, schools in different provinces and schools where the majority of learners and educators are black, coloured or Indian. This would allow researchers to gain results that can be generalised more in order to affect educational policies in the direction of just and inclusive recognition and representation of race in South African schools.

\section{REFERENCES}

Abdi, A. A. 2002. Culture, Education, and Development in South Africa: Historical and Contemporary Perspectives. Westport: Bergin and Garvey.

Ali, S. 2012. "Visual Analysis." In Researching Society and Culture, edited by C. Seale, 283-99. 3rd ed. London: Sage.

Ali, S., and M. Kelly. 2012. "Ethics and Social Research." In Researching Society and Culture, edited by C. Seale, 59-73. 3rd ed. London: Sage.

Amin, A. 2012. Land of Strangers. Cambridge: Polity Press.

Arber, R. 2008. Race, Ethnicity and Education in Globalised Times. Melbourne: Springer.

Ayers, C. W. 2010. “Social Justice.” In Encyclopedia of Curriculum Studies, edited by C. A. Kridel, 791-2. Los Angeles: Sage.

Banks, J. A. 2001. "Citizenship Education and Diversity: Implications for Teacher Education.” Journal of Teacher Education 52 (1): 5-16.

Baszile, D. T. 2010. "Ethnicity Research.” In Encyclopedia of Curriculum Studies, edited by C. A. Kridel, 347-9. Los Angeles: Sage.

Belluigi, D. Z. 2014. "The Paradox of 'Teaching' Transformation in Fine Art Studio Practice: Assessment in the South African Context." International Journal of Education through Art 10 (3): 349-62.

Cross, B. 2010. “Anti-Racism Theory.” In Encyclopedia of Curriculum Studies, edited by C. A. Kridel, 36-40. Los Angeles: Sage.

Delgado, S., and J. Stefanic. 2001. Critical Race Theory: An Introduction. New York: New York University Press. 
Department of Basic Education. 2011. "Curriculum and Assessment Policy Statement Grades R-3: Life Skills.” http://wced.pgwc.gov.za/documents/CAPS/lgsp.html\#FoundationPhase/FP-LifeSkills-eng. pdf*e-inf.html (accessed April 1, 2015).

Duncan, N. 2003. “'Race', Racism and the Media." In Social Psychology: Identities and Relationships, edited by K. Ratele and N. Duncan, 67-87. Paarl: University of Cape Town Press.

Durrheim, K., and J. Dixon. 2010. "Racial Contact and Change in South Africa." Journal of Social Issues 66 (2): 273-88.

Durrheim, K., X. Mtose, and L. Brown. 2011. Race Trouble: Race, Identity, and Inequality in a PostApartheid South Africa. Scottsville: University of KwaZulu-Natal Press.

Garrett, P. B. 2006. "Language Socialization.” In Encyclopedia of Language and Linguistics, edited by K. Brown, 604-13. Oxford: Elsevier.

Fanon, F. 1970. Black Skin, White Masks. Translated by C. L. Markmann. St. Albans: Paladin.

Fiske, E. B., and H. F. Ladd. 2004. "Racial Equity in Education: How Far Has South Africa Come?" Perspectives in Education 24 (2): 95-108.

Frankenberg, R. 1993. White Women, Race Matters: The Social Construction of Whiteness. Minneapolis: University of Minnesota Press.

Fraser, N. 1996. Social Justice in the Age of Identity Politics: Redistribution, Recognition, and Participation. The Tanner Lectures on Human Values, Stanford University, Stanford, CA, 30 April-2 May.

Fraser, N. 2009. Scales of Justice: Reimagining Political Space in a Globalizing World. New York: Columbia University Press.

Johnson, L., and P. Morris. 2010. “Towards a Framework for Critical Citizenship Education.” Curriculum Journal 21 (1): 77-96.

Hill, J. H. 1998. "Language, Race, and White Public Space." American Anthropologist 100 (3): 680-9.

Hook, D. 2003. "Franz Fanon and Racial Identity in Post-Colonial Contexts." In Social Psychology: Identities and Relationships, edited by K. Ratele and N. Duncan, 107-29. Paarl: University of Cape Town Press.

James, P. 2008. "Foreword." In Race, Ethnicity and Education in Globalised Times, edited by R. Arber. Melbourne: Springer.

Janesick, V. J. 2000. "The Choreography of Qualitative Research Design: Minuets, Improvisations, and Crystallisation." In Handbook of Qualitative Research, edited by N. K. Denzin and Y. S. Lincoln, 379-99. 2nd ed. Thousand Oaks: Sage.

Kumashiro, K. K. 2000. “Toward a Theory of Anti-Oppressive Education.” Review of Educational Research 70 (1): 25-53. 
Loxton, H. 2009. "Young Children's Self-Reports of Coping with Fears and Perceived Effectiveness of Coping Strategies in the South African Context." Anxiety, Stress and Coping 22 (3): 361-70.

Lynn, M., and L. Parker. 2006. "Critical Race Studies in Education: Examining a Decade of Research on US Schools.” The Urban Review 38 (4): 257-90.

Mayall, B. 2000. "Conversations with Children: Working with Generational Issues." In Research with Children: Perspectives and Practices, edited by P. Christensen and A. James, 123-31. London: Falmer Press.

Milner, H. R. 2007. "Race, Culture, and Researcher Positionality: Working through Dangers Seen, Unseen, and Unforeseen." Educational Researcher 36 (7): 388-400.

Mouton, J. 2001. How to Succeed in Your Master's and Doctoral Studies: A South African Guide and Resource Book. Pretoria: Van Schaik.

Nussbaum, M. 2002. "Education for Citizenship in an Era of Global Connection." Studies in Philosophy and Education 21 (4-5): 289-303.

Oloyede, O. 2009. "Critical Reflection on the Report of Ministerial Committee on Transformation, Social Cohesion and the Elimination of Discrimination in Public Higher Education." Perspectives in Education 27 (4): 426-34.

Pillay, S. 2009. "Translating 'South Africa': Race, Colonialism and Challenges of Critical Thought after Apartheid." In Re-Imagining the Social in South Africa: Critique, Theory and Post-Apartheid Society, edited by P. Vale and H. Jacklin, 235-67. Durban: University of KwaZulu-Natal Press.

Ratele, K., and T. Shefer. 2003. "Bodies in Apartheid.” In Social Psychology: Identities and Relationships, edited by K. Ratele and N. Duncan, 88-105. Paarl: University of Cape Town Press.

Roth, L. 2009. "Home on the Range: Kids, Visual Culture and Cognitive Equity." Cultural Studies Critical Methodologies 9 (2): 141-48.

Santas, A. 2000. “Teaching Anti-Racism.” Studies in Philosophy and Education 19 (4): 349-61.

Seekings, J. 2008. "The Continuing Salience of Race: Discrimination and Diversity in South Africa." Journal of Contemporary African Studies 26 (1): 1-25.

Seroto, J. 2012. "Citizenship Education for Africans in South Africa (1948-94): A Critical Discourse." Yesterday and Today 7 (3): 63-83.

Schieffelin, B. B., and E. Ochs. 1986. "Language Socialization.” Annual Review of Anthropology 15: 16391.

Smedley, A. 1998. “"Race' and the Construction of Human Identity.” American Anthropologist 100 (3): 690-702.

Statistics South Africa. 2014. General Household Survey. http:/www.statssa.gov.za/publications/P0318/ P03182014.pdf (accessed October 8, 2015). 
Stellenbosch University Language Centre. 2014. "Language Centre Style Guide." http://www0.sun.ac.za/ taalsentrum/assets/files/Style\%20Guide\%202014\%20final\%20for\%20web.pdf (accessed October 24, 2015).

Stevens, G., V. Franchi, and T. Swart. 2006. "Changing Contexts of Race and Racism: Problematics, Polemics and Perspectives." In A Race Against Time: Psychology and Challenges to Deracialization in South Africa, edited by G. Stevens, V. Franchi and T. Swart, 3-27. Pretoria: University of South Africa Press.

Stoll, L. C. 2014. "Constructing the Color-Blind Classroom: Teachers' Perspectives on Race and Schooling." Race, Ethnicity and Education 17 (5): 688-705.

Stovall, D. 2010. "Critical Race Theory.” In Encyclopedia of Curriculum Studies, edited by C. A. Kridel, 152-5. Los Angeles: Sage.

Wang, T. W. 2014. "Children's Drawings from China and the United States and Conceptions of Female Beauty." International Journal of Education through Art 10 (3): 363-79.

Warren, C. 2015. "How the New Apple Emoji Got Their Skin Tones: It's Not What You Think." http:// mashable.com/2015/02/26/diverse-emoji-explainer/\#naKdFK4rzsq6 (accessed October 6, 2015).

Weldon, G. 2010. "Post-Conflict Teacher Development: Facing the Past in South Africa." Journal of Moral Education 39 (3): 353-64.

Zimmermann, M., C. Levisen, T. G. Beck, and C. van Scherpenberg. 2015. "'Please Pass Me the Skin Coloured Crayon!' Semantics, Socialisation, and Folk Models of Race in Contemporary Europe." Language Sciences (49): 35-50. 